Mots. Les langages du politique

Que devient le pamphlet?

\title{
Actualité bibliographique. Les langages du politique
}

Josette Lefèvre

\section{OpenEdition}

Journals

Édition électronique

URL : https://journals.openedition.org/mots/19308

DOI : $10.4000 /$ mots. 19308

ISSN : 1960-6001

Éditeur

ENS Éditions

\section{Édition imprimée}

Date de publication : 30 novembre 2009

Pagination : 141-143

ISBN : 9782847881820

ISSN : 0243-6450

Référence électronique

Josette Lefèvre, «Actualité bibliographique. Les langages du politique », Mots. Les langages du politique [En ligne], 91 | 2009, mis en ligne le 30 novembre 2011, consulté le 23 avril 2022. URL : http://

journals.openedition.org/mots/19308; DOI : https://doi.org/10.4000/mots.19308

Ce document a été généré automatiquement le 23 avril 2022

(c) ENS Éditions 


\title{
Actualité bibliographique. Les langages du politique
}

\author{
Josette Lefèvre
}

\section{BIBLIOGRAPHIE}

ABLALI Driss, DUCARD Dominique éd., 2009, Vocabulaire des études sémiotiques et sémiologiques, Besançon, Presses universitaires de Franche-Comté, 312 p.

AUSSANT Émilie, 2009, Le nom propre en Inde. Considérations sur le mécanisme référentiel, Lyon, ENS Éditions, $166 \mathrm{p}$.

BADIR Sémir, DUCARD Dominique, 2009, Roland Barthes en cours (1977-1980) : un style de vie, Dijon, Éditions universitaires de Dijon, $160 \mathrm{p}$.

BÉLAND Martine, DUTRISAC Myrtô éd., 2009, Weimar ou l'hyperinflation du sens, Laval, Presses de l'université Laval, $227 \mathrm{p}$.

BRUN Josette éd., 2009, Interrelations femmes-médias dans l'Amérique française, Laval, Presses de l'université Laval, $254 \mathrm{p}$.

BUTON François, 2009, L'administration des faveurs. L'État, les sourds et les aveugles (1789-1885), Rennes, Presses universitaires de Rennes, $334 \mathrm{p}$.

CAMPA Riccardo, 2009, Langage et stratégie de communication, Paris, L'Harmattan, 180 p.

CABIN Philippe, DORTIER Jean-François, 2009, La communication. État des savoirs, Auxerre, Sciences Humaines, $415 \mathrm{p}$.

CHILTON Paul, 2006, Analysing Political Discourse. Theory and Practice, New York, Routledge, 240 p. 
COHEN Évelyne, 2009, La télévision sur la scène du politique. Un service public pendant les Trente Glorieuses, Paris, L'Harmattan, 204 p.

DACHEUX Éric éd., 2009, Les sciences de l'information et de la communication, Paris, CNRS, 182 p. DEBOUZY Marianne, 2009, Le monde du travail aux États-Unis. Les temps difficiles (1980-2005), Paris, L'Harmattan, $292 \mathrm{p}$.

DELAY Christophe, FRAUENFELDER Arnaud, PIGOT Nathalie, sCHULTHEIS Franz, 2009, Les classes populaires aujourd'hui. Portraits de familles, cadres sociologiques, Paris, L'Harmattan, 170 p.

Le discours et la langue, 2009, t. I (1), Revue de linguistique française et d'analyse du discours, Ethnotypes et sociotypes. Normes, discours, cultures, L. Calabrese, L. Rosier éd., Bruxelles, ULB. DRACIUS Suzanne, SAMLONG Jean-François, THÉOBALD Gérard, 2009, La crise de l'Outre-Mer français. Guadeloupe, Martinique, Réunion, Paris, L'Harmattan, 170 p.

DUMONS Bruno, POLLET Gilles éd., La fabrique de l'honneur. Les médailles et les décorations en France, $X I X^{e}-X X^{e}$ siècles, Rennes, Presses universitaires de Rennes, 240 p.

DURAMPART Michel éd., 2009, Sociétés de la connaissance. Fractures et évolutions, Paris, CNRS, 182 p. EKAMBO Jean-Chrétien, KIYINDOU Alain, MIYOUNA Ludovic-Robert éd., 2009, Communication et dynamiques de globalisation culturelle, Paris, L'Harmattan, $330 \mathrm{p}$.

ESQUENAZI Jean-Pierre, 2009, La vérité de la fiction. Comment peut-on croire que les récits de fiction nous parlent sérieusement de la réalité ?, Paris, Hermès Lavoisier, 208 p.

Études françaises, 2008, n 3, vol. 44, Microrécits médiatiques. Les formes brèves du journal, entre médiation et fiction, M.-E. Thérenty et G. Pinson éd., Montréal, Presses universitaires de Montréal, $172 \mathrm{p}$.

GAIOTTI Florence, 2009, Expériences de la parole dans la littérature de jeunesse contemporaine, Rennes, Presses universitaires de Rennes, $302 \mathrm{p}$.

GUILLEMETTE Lucie, HÉBERT Louis éd., 2009, Intertextualité, interdiscursivité et intermédialité, Laval, Presses de l'université Laval, 512 p.

GUILLOREL Hervé éd., 2008, Toponymie et politique. Les marqueurs linguistiques du territoire, Bruxelles, Bruylant, $234 \mathrm{p}$.

HAREL Simon, 2009, Espaces en perdition. Humanités jetables, t. II, Laval, Presses de l'université Laval, $301 \mathrm{p}$.

HAVU Éva éd., 2009, Langues et identités finlandaises, Paris, L'Harmattan, 176 p.

HUCK Dominique, KAHN René éd., 2009, Langues régionales, cultures et développement. Étude de cas en Alsace, Bretagne et Provence, Paris, L'Harmattan, $328 \mathrm{p}$.

LEFEBVRE Rémi, ROGER Antoine éd., 2009, Les partis politiques à l'épreuve des procédures délibératives, Rennes, Presses universitaires de Rennes, 222 p.

LITS Marc éd., 2009, Populaire et populisme, Paris, CNRS, 182 p.

MAINGUENEAU Dominique, 2009, Les termes clés de l'analyse du discours, Paris, Le Seuil, 143 p.

MEBIAME-AKONO Pamphile, 2009, De la linguistique aux sciences du langage. Évolution théorique d'une discipline, Paris, L'Harmattan, $154 \mathrm{p}$.

MENDOZE Gervais, 2009, Insécurité linguistique et appropriation du français en contexte plurilingue, Paris, L'Harmattan, $388 \mathrm{p}$. 
MFoUTOU Jean-Alexis, 2009, La langue de la nourriture, des aliments et de l'art culinaire au CongoBrazzaville, Paris, L'Harmattan, 236 p.

NOYER Jacques, 2009, Quand la télévision donne la parole au public. La médiation de l'information dans "L'Hebdo du médiateur », Lille, Presses universitaires du Septentrion, 326 p.

OLIVEIRA Isabelle, 2009, Nature et fonctions de la métaphore en science. L'exemple de la cardiologie, Paris, L'Harmattan, $220 \mathrm{p}$.

PINEIRA-TRESMONTANT Carmen éd., 2008, La présidentielle 2007 au filtre des médias étrangers, Paris, L'Harmattan, $386 \mathrm{p}$.

PUÉPI Bernard, 2009, Chroniques des pratiques politiques au Cameroun, Paris, L’Harmattan, 326 p.

REY Alain, 2009, L'esprit des mots, Rouen, Publications des universités de Rouen et du Havre, 48 p.

RIVIALE Philippe, 2009, La parole des prophètes. De la Tora à Simone Weil et Gracchus Babeuf, Paris, L'Harmattan, $262 \mathrm{p}$.

Semen, 2009, $\mathrm{n}^{\circ}$ 27, Critical Discourse Analysis 1. Les notions de contexte et d'acteurs sociaux, A. Petitclerc et P. Schepens éd., Besançon, Presses universitaires de Franche-Comté, 200 p. SIMONNOT Brigitte, GALLEZOT Gabriel éd., 2009, L'entonnoir. Google sous la loupe des chercheurs en sciences de l'information et de la communication, préface de H. Le Crosnier et en guise de postface, la nouvelle inédite « EnGooglés », de C. Doctorow, Caen, C \& F, 248 p.

TRACOL Matthieu, 2009, Changer le travail pour changer la vie? Genèse des lois Auroux, 1981-1982, préface de O. Wieviorka, Paris, L'Harmattan, 248 p.

WODAK Ruth, 2009, The Discourse of Politics in Action. Politics as Usual, New York, Palgrave McMillan, $256 \mathrm{p}$.

Wolton Dominique, 2009, Informer n'est pas communiquer, Paris, CNRS, 152 p.

\section{AUTEUR}

\section{JOSETTE LEFÈVRE}

Université de Picardie Jules Verne, CNRS (CURAPP)

josette.lefevre@u-picardie.fr 